\title{
Inserção laboral juvenil: contexto e opinião sobre definições de trabalho ${ }^{1}$
}

\author{
Luciana Dutra Thomé2 \\ Universidade Federal do Rio Grande do Sul, Porto Alegre-RS, Brasil \\ Alice Queiroz Telmo \\ Pontifícia Universidade Católica do Rio Grande do Sul, Porto Alegre-RS, Brasil \\ Silvia Helena Koller \\ Universidade Federal do Rio Grande do Sul, Porto Alegre-RS, Brasil
}

\begin{abstract}
Resumo: O presente artigo objetivou descrever aspectos relacionados ao contexto de inserção laboral dos jovens trabalhadores e não trabalhadores e a opinião destes em relação a definições de trabalho. Participam 7425 jovens, entre 14 a 24 anos de idade, ambos os sexos e nível socioeconômico baixo. Foi utilizado um questionário para levantamento de fatores de risco e proteção. Para análise de dados foram realizadas estatísticas descritivas, qui-quadrado e teste $t$ de Student. Constatou-se que os jovens trabalhadores encontram mais oportunidades de trabalho informal e recebem remuneração inferior a um salário mínimo, considerando que se dedicam cinco a oito horas diárias. Na amostra total, destacaram-se os significados de trabalho como "produção de algo útil" e "dinheiro". Estas dimensões podem estar refletindo a busca por um trabalho que construa algo produtivo para o indivíduo e sociedade. O público juvenil carece de um trabalho formal, benefícios trabalhistas e perspectivas de ascensão profissional.
\end{abstract}

Palavras-chave: condições de trabalho, jovens, significado, trabalho.

\section{Labor insertion of youth: the context and their opinion about work definitions}

\begin{abstract}
The aim of the study was to investigate the context of labor insertion of youth workers and non-workers and their opinion about work definitions. There were 7425 participants, aged between 14 and 24 years old, both genders, of low economic level. The instrument was a questionnaire about risk and protective factors. The data analysis included descriptive statistics, chi-square and Student $t$ test. Some results showed youth workers find more opportunities of informal work and receive remuneration lower then a minimum wage, considering that they work between 5 and 8 hours a day. In the total sample, the meanings of work as "useful production of something" and "money" were distinguished. These dimensions can reflect the search for a constructive and productive work for the individual and society, that provides survival conditions for them and their family. Youth lacks of a formal work, with benefits and perspective of professional ascension.
\end{abstract}

Keywords: working conditions, young adults, meaning, work.

\section{La inserción laboral de los jóvenes: contexto y opinión sobre definiciones de trabajo}

\begin{abstract}
Resumen: En este artículo se quiere describir aspectos relacionados con el contexto de inserción laboral de jóvenes trabajadores y no trabajadores, y su opinión sobre definiciones de trabajo. Participaron 7425 jóvenes, entre 14 y 24 años de edad, de ambos sexos y nivel socioeconómico bajo. Fue utilizado un cuestionario para identificar factores de riesgo y protección. Se realizaron análisis con estadísticos descriptivos, chi cuadrado y t de Student. Se constató que los jóvenes trabajadores encuentran más oportunidades de trabajo informal y reciben una remuneración inferior al salario mínimo, considerando que laboran entre 5 a 8 horas diarias. En la muestra total, se destacan los significados de trabajo como "producción de algo útil" y "dinero". Estas dimensiones pueden reflejar la búsqueda de un trabajo que construya algo productivo para el individuo y la sociedad. Los jóvenes carecen de un trabajo formal, de beneficios al trabajador y de perspectivas de ascenso profesional.
\end{abstract}

Palabras clave: condiciones de trabajo, jovenes, significado, trabajo.

O ser humano, em seu desenvolvimento, tende a orientar-se para um processo de independência: inicia os primeiros anos de vida como um ser dependente e, gradualmente, desenvolve sua autonomia. A etapa da juventude caracteriza-se pelo movimento de concretização desta independência, conquistando-a, entre outras formas, através da profissão.

1 Apoio: CNPq. Este trabalho é derivado da Dissertação de Mestrado defendida pela primeira autora, sob a orientação da última autora, no Programa de Pós-graduação em Psicologia da Universidade Federal do Rio Grande do Sul.

2 Endereço para correspondência:

Luciana Dutra Thomé. Universidade Federal do Rio Grande do Sul. Pósgraduação em Psicologia. Rua Ramiro Barcelos, 2600, sala 104. Porto Alegre-RS. CEP 90.035-003. E-mail: lucianaduth@gmail.com
Nas sociedades ocidentais, não existe uma única classificação - por parte de pesquisadores e instituições - do limite de idade da criança, do adolescente e dos jovens (Watarai \& Romanelli, 2005). De acordo com a Organização Internacional do Trabalho (OIT), a adolescência ocorre dos 15 aos 19 anos, enquanto a juventude corresponde à faixa etária de $20 \mathrm{a}$ 24 anos (Martins, 2000). Já o ECA (Estatuto da Criança e do Adolescente), de âmbito nacional, situa a adolescência entre 12 e 18 anos incompletos (Brasil, 1990). No presente trabalho, foi considerada a classificação proposta pela OIT.

Juventude configura uma categorização por idade, sendo necessária incorporação de aspectos sociais e históricos na sua avaliação (Margullis \& Urresti, 2008). No presente trabalho, levou-se em conta as delimitações dos processos de desenvolvimento em categorias fechadas, uma vez que 
estas possuem influências de valores institucionais, econômicos, socais e culturais. Nesse sentido, há de se considerar as peculiaridades do público atingido neste estudo, classificado, como jovens integrantes das "camadas populares". Esta categoria, proposta por Romanelli (1997), descrevia a população pobre dos centros urbanos, cuja condição de moradia era precária, com dificuldade de acesso a serviços de saúde, educação, saneamento básico e com renda familiar reduzida.

Nesse contexto, torna-se pertinente trazer a idéia de moratória juvenil proposta por Margullis e Urresti (2008), a qual considera as influências de aspectos relacionados às desigualdades sociais nos processos de desenvolvimento. Nesse sentido, os jovens dos setores médio e alto possuem, geralmente, oportunidades de estudar e postergar seu ingresso nas responsabilidades da vida adulta. Aos integrantes das camadas populares, por sua vez, são restritas as oportunidades de vivenciar esse processo de moratória, uma vez que, por exemplo, ingressam precocemente no mundo do trabalho e assumem responsabilidades familiares com menos idade (Margullis \& Urresti, 2008). Segundo Romanelli (1997), nas famílias de classe popular os filhos eram impelidos a buscarem sua autonomia e independência com relativa pouca idade.

Observa-se, portanto, que as formas de ser jovem dependem da idade, da geração, da classe social do marco institucional e do gênero. Os recursos que brindam moratória social não estão distribuídos uniformemente nos diversos setores sociais. Este processo faz, provavelmente, com que o período juvenil nos setores populares seja mais curto em relação às classes médias e altas (Margullis \& Urresti, 2008).

Ouro aspecto a considerar é que, na infância, o projeto profissional dos indivíduos já começa a ser construído, influenciado pelas representações sociais das profissões, principalmente a dos pais (Soares, 2001). Para muitos jovens, a experiência ou inexperiência de inserção no mercado laboral torna-se fator fundamental no processo de formação de sua identidade (Bajoit \& Franssen, 1967/2007; Sarriera, Silva, Kabbas, \& Lopes, 2001).

No Brasil, o contexto de inserção laboral dos jovens mostra-se desfavorável em alguns aspectos, pois a fragilidade e instabilidade do atual contexto podem tornar o jovem mais vulnerável ao entrar no mercado de trabalho. Vulnerabilidade diz respeito à pré-disposição individual para desenvolver comportamentos ineficazes ou psicopatologia em situações de crise: desnutrição, família desestruturada, desemprego, dentre outros (Pesce, Assis, Santos, \& Oliveira, 2004; Sapienza \& Pedromônico, 2005). Nesse sentido, as condições de trabalho dos jovens, quando desprotegidas, podem vulnerabilizá-los.

Já em 2000, destacou-se a questão do trabalho remunerado entre os jovens, tanto entre as áreas de maior interesse como as de maior preocupação. A dificuldade de inserção no mercado de trabalho tem sido percebida, até a atualidade, como o principal componente negativo de sua condição juvenil, vulnerabilizando-os (IBASE/POLIS, 2005; Instituto
Cidadania, 2003). No Brasil, este panorama é particularmente preocupante: o desemprego atinge 3,5 milhões de jovens com idades entre 16 e 24 anos, cerca de $45 \%$ da força de trabalho nacional (OIT, 2005). Em pesquisa realizada por Tokman, Corrochano e Gouvêa (2003) foram identificadas quatro causas para desemprego juvenil: (a) insuficiência dinâmica da economia e características do crescimento; (b) exigências e expectativas dos jovens em relação ao emprego esperado; (c) insuficiência do capital humano quanto à educação e experiência; (d) características de rigidez do mercado de trabalho, como custos de contratação e demissão dos jovens e níveis salariais mínimos. Ainda, de acordo com o IBASE/POLIS (2005), a "qualificação profissional dos jovens" destaca-se como demanda associada com a realidade de desemprego presente na vida dos jovens participantes.

A inserção dos jovens no trabalho tem ocorrido de forma cada vez mais precária, em um contexto laboral marcado pela informalidade e pelo desemprego. Em geral, o ingresso dos jovens no mercado de trabalho inicia-se com vínculos ocupacionais mais frágeis e transitórios, até o estabelecimento de um vínculo mais duradouro. As mudanças no mundo do trabalho trouxeram para toda a População Economicamente Ativa (PEA) intensas transições em diferentes situações ocupacionais. Os jovens, no entanto, parecem ser os mais afetados (Camarano \& Melo, 2006).

Outro aspecto a considerar é que a política neoliberal adotada pela economia globalizada causa, em última instância, a precarização das relações de trabalho e, consequentemente, o desemprego, o que eleva a vulnerabilidade social, a pobreza e a exclusão (Lima \& Minayo-Gomes, 2003). A dificuldade de se discriminar essas situações gera sofrimento nos jovens, ao atribuírem a si próprios as causas da incapacidade de se integrar ao mercado de trabalho (Gonçalves, 2008; Lehman, 1998). Na "sociedade organizacional", filha da sociedade centrada no mercado, a pessoa passa a ter um valor correspondente à importância de seu trabalho ou à sua capacidade produtiva (Mattos, 1992).

No que se refere à dinâmica empresarial, muitas vezes, esta estabelece uma relação contínua de dominação/subordinação, ativando, nos jovens, a necessidade de sujeição às leis do mercado de trabalho. Estes, por sua vez, aprendem rapidamente a exigência de tal condição para ganhar dinheiro e garantir o sustento (Asmus e cols., 2005; Oliveira \& Robazzi, 2001).

Identifica-se, portanto, que a categoria social trabalho tem enfrentado, nos últimos anos, diversas transformações no que tange às relações de trabalho, à reestruturação reprodutiva, à competitividade e ao desemprego. É atravessada pela cultura do desempenho, da excelência, da competição exacerbada, da produtividade e da fidelidade aos objetivos e idéias do empresariado. A população juvenil é um dos segmentos sociais que mais sofre suas conseqüências (Câmara, Sarriera, \& Pizzinato, 2004), o que se agrava pelos entraves presentes na inserção de jovens no mercado de trabalho, como o preconceito e precariedade da educação oferecida 
pelo sistema escolar. As organizações consideradas modernas valorizam qualidade, produtividade, autonomia, criatividade, versatilidade, polivalência e flexibilidade (Batista \& Codo, 2002; Gonçalves, 2008; Lima \& Minayo-Gomes, 2003; Nardi \& Yates, 2005; Sato, 2002), de forma a desconsiderar, numa certa medida, as repercussões do trabalho na vida dos indivíduos.

$\mathrm{O}$ modelo cultural vigente na sociedade industrial reforça este processo de tensão psicossocial, uma vez que se baseia na centralidade da ética do trabalho, a qual possui como eixo focal a idéia de rendimento. Para este modelo: (a) a atividade laboral deve ser socialmente útil, contribuindo de alguma forma para o coletivo; (b) o indivíduo deve receber uma retribuição justa a sua contribuição; (c) primeiramente deve ocorrer o esforço e o trabalho deve ser executado, só então a retribuição virá como conseqüência; (d) a contribuição é medida pelo esforço de realizar o trabalho; (e) os trabalhadores participam do mundo do trabalho através de outras instâncias, como a comunidade e sindicato. Sua participação não é apenas individual, mas também faz parte de um grupo (Bajoit \& Franssen, 1967/2007).

Nesse sentido, a vivência profissional ultrapassa o âmbito exclusivamente laboral, uma vez que não se restringe apenas ao ato de trabalhar. Esta influencia o modo de pensar, agir e sentir despertados na pessoa em seu cotidiano de trabalho, e estes, por sua vez, são transportados para a vida familiar e comunitária. Portanto, é necessário maturidade física, mental e moral para sua execução, de modo que a atividade laboral seja promotora de significado e prazer para os trabalhadores (Amazarray, Dutra-Thomé, Poletto, \& Koller, 2007). Além disso, a complexidade do circuito sujeito-trabalho- significado proporciona maior prazer no trabalho, enquanto que o rompimento deste circuito ocasiona sofrimento (Codo \& Lago, 2006; Tolfo \& Piccinini, 2007).

Alguns estudos apontam que a visão juvenil do trabalho tem sido descrita como: um meio de ajudar as famílias, de adquirir independência financeira e uma maneira de conquistar liberdade (Asmus, Raymundo, Barker, Pepe, \& Ruzany, 2005; Campos \& Francischini, 2003; Guimarães \& Romanelli, 2002; Oliveira \& Robazzi, 2001). Em oficina realizada com estudantes universitários (Coutinho \& Gomes, 2006), foi encontrada uma distinção nos significados de trabalho e emprego. Para emprego o significado atribuído foi uma forma de produção de riquezas e, para trabalho, o significado encontrou-se associado ao relacionamento com outras pessoas e a um sentido pessoal constituinte de identidade. Identificou-se que há uma busca por um trabalho satisfatório e prazeroso, que supra as necessidades dos sujeitos nos planos afetivo, cognitivo, social e financeiro.

O trabalho ainda possui uma dimensão instrumental (fonte de ganhos, ocupação do tempo e status social) e uma dimensão expressiva (realização social e pessoal). Em estudo francês realizado com jovens no final da década de 60 (Bajoit \& Franssen, 1967/2007), os entrevistados descreveram que gostar do trabalho e estar em um bom ambiente é um critério tão importante quanto o salário. Essa descrição, segundo os autores, demonstrou que, ao trabalharem os jovens exercem não apenas uma atividade produtiva, que lhes proporciona independência financeira, mas também vivenciam uma experiência central de socialização.

Outra pesquisa comparou os significados atribuídos ao trabalho de jovens venezuelanos empregados e desempregados, de classe popular, entre 15 e 17 anos (Jesús \& Ordaz, 2006). Para estes, o trabalho vincula-se com vivências emocionais positivas, relacionadas com a satisfação de necessidades de valorização e reconhecimento, propiciando ao individuo independência material e psicológica.

Em estudo realizado com jovens de classe econômica baixa que estudam e trabalham, pesquisou-se qual a representação social do trabalho e da relação trabalho-estudo. As palavras encontradas pelos jovens para descrever esta dupla jornada foram: "cansativo", "difícil", "necessidade", "muita responsabilidade", "estressante", "ruim", "correria" e "conciliar". Palavras positivas também foram expressas como, por exemplo, "bom", sendo esta carregada por um sentido simbólico que remete à dimensão moral do trabalho, na qual estão expressos os valores que enaltecem o trabalho. A palavra "esforço", também citada pelos jovens, pode ser pensada em dois sentidos: (1) como um atributo pessoal positivo necessário para administrar a dupla jornada trabalho-estudo e (2) como a experiência de vida que exige esforço (Fischer, Oliveira, Teixeira, Teixeira, \& Amaral, 2003).

Dados do IBASE/POLIS (2006) revelaram que, na opinião dos jovens, não é possível conciliar o tempo de escola com o trabalho, pois não existe um diálogo entre estas duas instituições. Revela-se uma possível dissociação entre os diferentes âmbitos de convívio dos jovens, uma vez que, em muitos aspectos, as dimensões do trabalho, que envolvem contradições entre valores individuais e coletivos, espaço público e privado e condições materiais de vida e de trabalho, são desconsideradas (Souza \& Figueiredo, 2004), o que pode ser prejudicial.

A partir do exposto, é possível caracterizar as relações no contexto atual de trabalho como fragilizadas. Há instabilidade no emprego, não respeito às leis trabalhistas, elevada competitividade, condições físicas e relacionais precárias, entre outros. Dessa forma, torna-se pertinente investigar o que os jovens pensam em relação ao significado do trabalho e de que forma eles estão se inserindo ou não no mercado laboral.

Assim, o presente artigo teve por objetivo: (a) descrever aspectos relacionados ao contexto de inserção laboral dos jovens brasileiros trabalhadores e não trabalhadores (tipo de trabalho, renda mensal média, auxílio, dinheiro economizado e horas diárias dedicadas ao trabalho) e (b) descrever a opinião de jovens trabalhadores e não trabalhadores em relação às seguintes definições de trabalho: produção do que é útil, dinheiro, honra, atividade intelectual, esforço, emprego, obrigação religiosa, saúde, identidade e mercadoria. 


\section{Método}

\section{Delineamento}

Estudo de caráter exploratório descritivo, que faz parte de uma Pesquisa Nacional sobre Fatores de Risco e Proteção da Juventude Brasileira, que vem sendo realizado em sete capitais e três cidades de médio porte do país. Utilizou-se a base de dados desta Pesquisa, do qual foram extraídas as informações referentes à experiência laboral.

\section{Participantes}

Participaram do estudo 7425 jovens de 14 a 24 anos de idade, de ambos os sexos, nível socioeconômico baixo, de sete capitais brasileiras: Porto Alegre (Região Sul), Recife (Nordeste), São Paulo e Belo Horizonte (Sudeste), Brasília e Campo Grande (Centro-Oeste) e Manaus (Norte) - e de três cidades: Arcos (Minas Gerais), Presidente Prudente (São Paulo) e Maués (Amazonas). Os jovens do estudo foram estudantes de escolas públicas ou participantes de instituições de atendimento (ONGs, centros comunitários, entre outras).

\section{Instrumentos}

Para a realização da Pesquisa Nacional, foi utilizado um questionário para levantamento de fatores de risco e proteção, produzido para o estudo Juventude Brasileira (Koller, Cerqueira-Santos, Morais, \& Ribeiro, 2005). O instrumento completo contém 109 questões.

\section{Procedimentos de coleta de dados}

A pesquisa foi aprovada pelo Comitê de Ética em Pesquisa da Universidade Federal do Rio Grande do Sul, protocolo número 2006533. Os aspectos éticos do estudo garantiram a integridade dos participantes. Além do Termo de Consentimento Livre e Esclarecido individual, foi dada a garantia de sigilo das informações pessoais, assim como disponibilizada a assistência do grupo de pesquisa, caso algum participante necessitasse de apoio psicológico (Resoluções $n^{\circ}$ 196/1996, do Conselho Nacional de Saúde e no 016/2000 do Conselho Federal de Psicologia).

A abordagem inicial dos participantes envolveu a apresentação dos objetivos da pesquisa e da equipe às escolas e às instituições de atendimento escolhidas por bairro em cada capital. A partir da autorização para execução da coleta de dados, os jovens eram reunidos para explicação sobre a natureza do estudo e sobre o caráter confidencial das informações a serem obtidas, descrição sobre o uso dos dados e a leitura do Termo de Consentimento Livre e Esclarecido.

Para abordar jovens em nível socioeconômico baixo, foram verificados os indicadores das condições sócio-demográficas de cada uma das capitais e cidades. Para todas elas, com exceção de São Paulo, foram utilizados os indicadores: rendimento do chefe da família, características educacionais da população residente (grau de instrução do chefe de domicílio, grau de instrução por faixa etária, nível de acessibilidade aos equipamentos educacionais públicos - escolas e creches), situação do domicílio (tipo de construção), existência de água encanada e rede de esgoto, com base nos dados do Instituto Brasileiro de Geografia e Estatística [IBGE] (Censo 2000). Para São Paulo foi utilizado, além destes indicadores, o Índice de Desenvolvimento Humano (IDH), uma vez que a Prefeitura Municipal disponibiliza o valor destes índices por bairro - em geral as demais Prefeituras Municipais fornecem IDH para a cidade como um todo e não por bairros (por exemplo, Porto Alegre =0,865; Recife =0,797).

Bairros que apresentavam índices abaixo dos dez por cento do valor total da cidade foram escolhidos a princípio. A partir de duas listas de escolas (Municipais e Estaduais), encontradas nos sites das respectivas Secretarias de Educação, foram relacionadas às escolas que atendiam a cada bairro sorteado. Foi, então, realizado um novo sorteio para selecionar uma escola para cada bairro. Dessa forma, foram listadas dez escolas. Em média, em cada escola deveriam participar cerca de 100 jovens. No entanto, esse número apresentou uma ligeira variação, uma vez que algumas escolas possuíam apenas o Ensino Fundamental ( $5^{\mathrm{a}}$ a $8^{\mathrm{a}}$ série), enquanto que outras possuíam até o Ensino Médio.

Em cada escola, foram contempladas turmas dos três turnos (manhã, tarde e noite), por possibilitarem acesso a perfis diferenciados de jovens. Turmas com características extremas, como "a melhor" ou " a pior" segundo avaliação da própria escola, foram evitadas. Em algumas escolas, mais de uma turma foi agrupada numa sala para a aplicação do questionário, uma vez que participantes na faixa etária desejada encontravam-se espalhados por várias salas diferentes da escola. Os jovens que não freqüentam a escola foram acessados através de instituições comunitárias dos bairros sorteados.

\section{Procedimentos de análise dos dados}

Para análise de dados foram realizadas estatísticas descritivas (freqüência, porcentagem, média e desvio-padrão), qui-quadrado e teste $t$ de Student. No caso do qui-quadrado, como se trabalhou com variáveis que possuem mais de dois níveis, foram apresentados os resíduos padronizados ajustados maiores que $+1,96$ e menores que $-1,96$, indicando, respectivamente, um percentual de casos significativamente maior e menor que o esperado, deslocado a respectiva categoria. Portanto, os sinais positivo e negativo indicam qual categoria apresenta diferença estatisticamente significativa entre os grupos de comparação. O teste $t$ de Student foi utilizado na comparação das médias entre grupos de trabalhadores e não trabalhadores, no caso, de amostras independentes. O critério de significância utilizado para ambas as análises bivariadas foi $p<0,01$, a fim de que os valores estatisticamente significativos obtivessem um critério de maior rigor.

\section{Resultados e Discussão}

Observa-se, na Tabela 1 , que 7,5\% dos jovens trabalhadores responderam que não estão trabalhando nem 
procurando trabalho. Esta questão, num primeiro momento, pode parecer incompatível, pois se eles trabalham não poderiam marcar positivamente esta resposta. Todavia, a pergunta inicial, ou seja, se o jovem trabalha ou não (questão 55) referia-se ao período atual ou até 12 meses que antecederam a coleta de dados. Nesse sentido, o jovem pode ter marcado que trabalhou nos 12 meses que antecederam a coleta de dados, mas, no período em que respondeu o questionário, poderia não estar mais trabalhando e nem procurando trabalho - o que explicaria a marcação positiva da resposta.

Tabela 1

Percentuais (freqüências) da variável tipo de trabalho ${ }^{\text {a }}$

\begin{tabular}{|c|c|c|c|c|}
\hline & $\begin{array}{l}\text { Total } \\
\%(f) \\
\end{array}$ & $\begin{array}{c}\text { Trabalhadores } \\
\%(f) \\
\end{array}$ & $\begin{array}{c}\text { Não trabalhadores } \\
\%(f) \\
\end{array}$ & $p$ \\
\hline Não trabalha e não está procurando trabalho ${ }^{b}$ & $23,5(1658)$ & $7,5(210)-$ & $34,0(1448)+$ & $<0,0001^{*}$ \\
\hline Não trabalha e está procurando trabalho ${ }^{c}$ & $40,0(2830)$ & $25,1(699)-$ & $49,7(2131)+$ & $<0,0001^{*}$ \\
\hline Trabalha com carteira assinada ${ }^{\mathrm{d}}$ & $12,8(900)$ & $29,7(826)+$ & $1,7(74)-$ & $<0,0001 *$ \\
\hline Trabalha sem carteira assinada ${ }^{\mathrm{e}}$ & $10,4(729)$ & $24,3(677)+$ & $1,2(52)-$ & $<0,0001 *$ \\
\hline Trabalha por conta própria ${ }^{f}$ & $5,1(359)$ & $9,6(267)+$ & $2,2(92)-$ & $<0,0001^{*}$ \\
\hline Faz bicos $\mathrm{g}$ & $12,5(878)$ & $17,6(489)+$ & $9,1(389)-$ & $<0,0001^{*}$ \\
\hline Realiza trabalhos voluntários ${ }^{\mathrm{h}}$ & $5,8(407)$ & $6,1(171)$ & $5,5(236)$ & 0,289 \\
\hline Ajuda em casa ${ }^{\mathrm{i}}$ & $42,3(2990)$ & $30,6(851)-$ & $50,0(2139)+$ & $<0,0001^{*}$ \\
\hline Trabalha para outrem $^{j}$ & $2,0(143)$ & $2,4(66)$ & $1,8(77)$ & 0,102 \\
\hline
\end{tabular}

Nota. ${ }^{\mathrm{a}} \%$ (n); ${ }^{\mathrm{b}} \mathrm{n}=7047 ;{ }^{\mathrm{c}} \mathrm{n}=7073 ;{ }^{\mathrm{d}} \mathrm{n}=7042 ;{ }^{\mathrm{e}} \mathrm{n}=7037 ;{ }^{\mathrm{f}} \mathrm{n}=7036 ;{ }^{\mathrm{g}} \mathrm{n}=7034 ;{ }^{\mathrm{h}} \mathrm{n}=7037 ;{ }^{\mathrm{i}} \mathrm{n}=7063 ;{ }^{\mathrm{j}} \mathrm{n}=7034$.

Os símbolos $+\mathrm{e}-$ significam respectivamente um percentual de casos maior e menor que o esperado deslocados para a categoria (+: resíduo padronizado ajustado $>+1,96$; -: resíduo padronizado ajustado $<-1,96)$. ${ }^{*} p<0,01$.

Na presente amostra, identificou-se que mais jovens não trabalhadores não estão procurando trabalho (34\%) em relação aos jovens que trabalham $(7,5 \%)\left(\chi^{2}=653,5\right.$; $F=1 ; p<0,0001$ ) (Tabela 1). Ao mesmo tempo, houve um percentual maior de jovens não trabalhadores que está procurando trabalho $(49,7 \%)$ em relação aos jovens trabalhadores $(25,1 \%)(\chi 2=425,6 ; F=1 ; p<0,0001)$.

Torna-se pertinente, no que se refere aos jovens que procuram uma ocupação, assinalar a fragilidade da vivência do desemprego. Esta pode levar o jovem não trabalhador ao sofrimento, vulnerabilizando-o diante da necessidade de buscar uma atividade laboral e aumentando o risco de que o mesmo se oriente para uma inserção profissional precária (Campos \& Francischini, 2003; Oliveira \& Robazzi, 2001; Tokman e cols., 2003) - o que é reforçado pela lógica da centralidade da ética do trabalho, focada na idéia de rendimento, uma vez que, através da profissão, a pessoa tem a oportunidade de produzir algo socialmente útil e receber por seu esforço (Bajoit \& Frassen, 1967/2007). Segundo estudo de Sarriera, Schwarez e Câmara (1996), os jovens que possuíam um trabalho fixo demonstraram os níveis mais elevados de bem-estar psicológico, enquanto os jovens desempregados apresentaram em menor número os níveis "muito bom" e "bom" de bem-estar psicológico. Outro aspecto a considerar é que, de acordo com o Panorama Laboral da OIT (2009), ainda que em 2008 o desemprego na América Latina e no Caribe tenha diminuído pelo quinto ano consecutivo para $7,5 \%$, a crise atual coloca em risco o emprego de até 2,4 milhões de pessoas em 2009.

No que se refere à realização de "bicos", houve um percentual maior de jovens trabalhadores que os realizam $(17,6 \%)\left(\chi^{2}=109,78 ; F=1 ; p<0,0001\right)$ em relação aos jovens não trabalhadores $(9,1 \%)(p<0,0001)$. No caso dos jovens não trabalhadores que marcaram positivamente que fazem "bicos", a não formalidade do trabalho pode tê-los levado a marcarem que não trabalham, o que justificaria sua inclusão neste grupo e não no de trabalhadores. É possível inferir que, para estes jovens, a atividade laboral está relacionada com o contrato formal de trabalho, que possui o termo "emprego" como referência (Fó, 2006; Nardi, 2006).

A atividade de ajuda em casa apresentou um percentual significativamente maior de jovens não trabalhadores $(50,0 \%)$ sobre os jovens trabalhadores $(30,6 \%)\left(\chi^{2}=260,6\right.$; $F=1 ; p<0,0001)$ (Tabela 1$)$, o que pode demonstrar a vinculação direta de trabalho com tarefas cotidianas e remuneradas que ocorrem fora do âmbito familiar. A atividade doméstica parece não ser reconhecida como uma atividade laboral. Ainda nessa lógica, no que se refere à realização de trabalhos voluntários e trabalhar para outrem gratuitamente, os jovens de ambos os grupos se assemelham $(p>0,01)$, o que pode estar indicando que, para eles, torna-se difícil definir se as atividades não remuneradas caracterizam ou não, uma atividade laboral. 
Tabela 2

Percentuais (Freqüências) da variável tipo de trabalho ${ }^{\text {a }}$

\begin{tabular}{lc}
\hline & $\begin{array}{c}\text { Trabalhadores } \\
\text { \%(f) }\end{array}$ \\
\hline Não trabalha e não está procurando trabalho $^{\mathrm{b}}$ & $4,9(210)$ \\
Não trabalha e está procurando trabalho $^{\mathrm{c}}$ & $16,4(699)$ \\
Trabalha com carteira assinada $^{\mathrm{d}}$ & $19,4(826)$ \\
Trabalha sem carteira assinada $^{\mathrm{e}}$ & $15,9(677)$ \\
Trabalha por conta própria $^{\mathrm{f}}$ & $6,3(267)$ \\
Faz bicos $^{\mathrm{g}}$ & $11,5(489)$ \\
Realiza trabalhos voluntários $^{\mathrm{h}}$ & $4,0(171)$ \\
Ajuda em casa $^{\mathrm{i}}$ & $20,0(851)$ \\
Trabalha para outrem $^{\mathrm{j}}$ & $1,6(66)$ \\
\hline
\end{tabular}

Nota. ${ }^{\text {a } \% ~(n) ; ~}{ }^{\mathrm{b}} \mathrm{n}=7047 ;{ }^{\mathrm{c}} \mathrm{n}=7073 ;{ }^{\mathrm{d}} \mathrm{n}=7042 ;{ }^{\mathrm{e}} \mathrm{n}=7037 ;{ }^{\mathrm{f}} \mathrm{n}=7036 ;{ }^{\mathrm{g}} \mathrm{n}=7034 ;{ }^{\mathrm{h}}$ $\mathrm{n}=7037 ;{ }^{\mathrm{i}} \mathrm{n}=7063 ;{ }^{\mathrm{j}} \mathrm{n}=7034$

$* p<0,01$

Apesar de também se referir à variável Tipo de trabalho, os dados da tabela 2 diferenciam-se dos dados da tabela 1 , uma vez que se referem exclusivamente ao grupo de jovens trabalhadores. Portanto, a tabela 2 propicia a visualização das percentagens dentre o grupo de trabalhadores.

Nesse contexto, em relação aos jovens que exercem atividade remunerada, foi possível identificar que existe maior concentração de jovens, em primeiro lugar, que trabalham com carteira assinada (19,4\%); em segundo, sem carteira assinada $(15,9 \%)$; em terceiro, que realizam "bicos" $(11,5 \%)$ e, por último, que trabalham por conta própria $(6,3 \%)$ (Tabela 2). Constatou-se uma porcentagem superior de jovens que trabalham informalmente $(33,7 \%)$, uma vez que apenas $19,4 \%$ possui carteira assinada. Dados do Censo Demográfico de 2000 já indicavam que, na faixa etária entre 10 a 19 anos, encontrava-se a maior proporção de trabalhadores sem carteira de trabalho, portanto excluídos do mercado formal de trabalho (IBGE, 2000). Estudo desenvolvido por Sarriera e cols. (2001) identificou, além da fragilidade dos processos seletivos vivenciados pelos jovens, que as possibilidades de ascensão profissional eram restritas, os benefícios recebidos elementares e, eventualmente, o trabalho inicial proporcionado era sem a carteira de trabalho registrada. Ainda, de acordo com o IBASE/POLIS (2005) a maioria dos jovens pesquisados encontrava-se em situação de desemprego, grande parte dos jovens trabalhavam sem carteira assinada, inclusive aqueles que já haviam constituído família ou tinham filhos.

A partir deste quadro, é possível pensar que os jovens enfrentam dificuldades para se inserir no mercado de trabalho e, aliado a isso, não possuem garantia legal de nele continuar. O contexto trabalhista fragilizado coloca os jovens em uma situação de trabalho informal, que pode vir a lhe exigir dedicação como qualquer outro tipo de atividade profissional, sem garantir-lhe nenhum direito. Desta forma, o(a) jovem torna-se vulnerável no começo de sua trajetória laboral, momento em que ele necessitaria de apoio moral e legal.

Tabela 3

Percentuais (freqüências) renda mensal média, auxilio, dinheiro economizado, horas diárias dedicadas ao trabalho ${ }^{\mathrm{ab}}$

\begin{tabular}{lc}
\multicolumn{1}{c}{ Variável } & $\begin{array}{c}\text { Trabalhadores } \\
\text { \%o(f) }\end{array}$ \\
\hline Renda mensal média $^{j}$ & $1866(88,5)$ \\
Até 400 reais & $196(9,3)$ \\
De 401 a 800 reais & $28(1,3)$ \\
De 801 a 1200 reais & $19(0,9)$ \\
Mais que 1200 reais & $42,4(897)$ \\
Auxílio do trabalho ${ }^{1}$ & $45,2(947)$ \\
Dinheiro economizado a partir do trabalho ${ }^{\mathrm{n}}$ & \\
Horas diárias dedicadas ao trabalho ${ }^{\circ}$ & $20,85(396)$ \\
1-4 & $63,13(1199)$ \\
5-8 & $14,00(266)$ \\
9-12 & $0,789(15)$ \\
13-16 & $1,21(23)$ \\
Acima de 16
\end{tabular}

Nota $\mathrm{a} \%(\mathrm{n}) ;{ }^{\mathrm{b}}$ Perguntas realizadas apenas para quem está trabalhando; ${ }^{j} \mathrm{n}=2109 ;{ }^{1} \mathrm{n}=2117 ;{ }^{\mathrm{m}} \mathrm{n}=2064 ;{ }^{\mathrm{n}} \mathrm{n}=2093 ;{ }^{\circ} \mathrm{n}=1899$.

Este panorama torna-se mais expressivo ao se analisarem as variáveis renda mensal média, auxílio, dinheiro economizado a partir do trabalho e horas diárias dedicadas ao trabalho (Tabela 3), também investigadas apenas no grupo de jovens trabalhadores. Constatou-se que um número relativamente elevado de jovens recebe remuneração baixa $88,5 \%$, isto é, inferior ao salário mínimo - ainda que trabalhem entre 5 e 8 horas diárias $63,13 \%$ (Tabela 3). Somado a isso, foi identificado que mais da metade $(57,6 \%)$ dos jovens que trabalham não recebiam nenhum tipo de auxílio (como vale-transporte ou vale-alimentação), e apenas $45,2 \%$ dos jovens que trabalham conseguiram economizar alguma parte do dinheiro recebido. Tal quadro corrobora os diversos estudos referentes às atividades laborais juvenis (Bastos, 2003; Campos \& Francischini, 2003; Lima \& Minayo-Gomes, 2003; Oliveira \& Robazzi, 2001; Sarriera e cols., 2001; Traverso-Yépez, 2002). 
Tabela 4

Opinião sobre definições de trabalho ${ }^{a b}$

\begin{tabular}{lcccc}
\hline \multicolumn{1}{c}{ Trabalho é... } & Total & Trabalhadores & Não trabalhadores & p \\
\hline produção do que é útil c $^{c}$ & $2,69(0,585)$ & $2,70(0,576)$ & $2,68(0,589)$ & 0,333 \\
dinheiro $^{\text {e }}$ & $2,59(0,639)$ & $2,58(0,645)$ & $2,59(0,635)$ & 0,589 \\
honra $^{\text {d }}$ & $2,48(0,724)$ & $2,48(0,735)$ & $2,48(0,715)$ & 0,951 \\
atividade intelectual $^{\mathrm{f}}$ & $2,41(0,705)$ & $2,43(0,701)$ & $2,39(0,707)$ & 0,046 \\
esforço $^{\mathrm{g}}$ & $2,16(0,827)$ & $2,21(0,825)$ & $2,13(0,825)$ & $<0,0001^{*}$ \\
emprego $^{\text {h }}$ & $2,14(0,813)$ & $2,12(0,828)$ & $2,16(0,803)$ & 0,102 \\
obrigação religiosa $^{\text {i }}$ & $2,12(0,841)$ & $2,12(0,848)$ & $2,13(0,836)$ & 0,781 \\
saúde $^{\text {j }}$ & $1,83(0,800)$ & $1,86(0,813)$ & $1,80(0,790)$ & 0,002 \\
identidade $^{1}$ & $1,80(0,787)$ & $1,85(0,798)$ & $1,76(0,777)$ & $<0,0001^{*}$ \\
mercadoria $^{\mathrm{m}}$ & $1,76(0,793)$ & $1,83(0,816)$ & $1,72(0,772)$ & $<0,0001^{*}$ \\
\hline
\end{tabular}

Nota. ${ }^{a}$ Escala tipo Likert: Discordo $=1 ;$ Não concordo nem discordo $=2 ;$ Concordo $=3 ;{ }^{\mathrm{b}} \mathrm{M}(S D) ;{ }^{\mathrm{c}} \mathrm{n}=6897 ;{ }^{\mathrm{d}} \mathrm{n}=6697 ;{ }^{\mathrm{e}} \mathrm{n}=6805 ;{ }^{\mathrm{f}} \mathrm{n}=6624 ;{ }^{\mathrm{g}} \mathrm{n}=6896 ;{ }^{\mathrm{h}} \mathrm{n}=6781$; ${ }^{\mathrm{i}} \mathrm{n}=6874 ;{ }^{\mathrm{j}} \mathrm{n}=6620 ;{ }^{1} \mathrm{n}=6433 ;{ }^{\mathrm{m}} \mathrm{n}=6534 .{ }^{*} p<0,01$.

Uma vez identificado um contexto vulnerável de inserção laboral para os jovens participantes, torna-se pertinente considerar a opinião que os mesmos possuem sobre definições de trabalho. Esta sofre influência do contexto social, político e econômico no qual o indivíduo está inserido e, mais diretamente, da sua experiência cotidiana de trabalho ou não trabalho.

Nesse sentido, a média da amostra total em relação às definições de trabalho (Tabela 4) apresentou-se na seguinte ordem decrescente: produção do que é útil, dinheiro; honra; atividade intelectual; esforço; emprego; obrigação religiosa; saúde; identidade e mercadoria. A média mais elevada da amostra total aproxima-se das descrições de Jesús e Ordaz (2006), a partir da qual a importância do trabalho se apresenta em duas fontes principais: o desenvolvimento pessoal ou profissional - ou seja, meio de adquirir experiência e aprendizagem - e a econômica - uma vez que muitos o vêem como forma de subsistência para si e sua família.

O desenvolvimento pessoal e profissional apresentou-se através da definição "produção do que é útil", em primeiro lugar. Esta se vincula à realização de uma obra que dá reconhecimento ao ser humano, uma herança histórica recebida e transmitida para outros indivíduos, definida no próprio dicionário da língua portuguesa (Albornoz, 1986). Já a definição de trabalho como "dinheiro" ocupou o segundo lugar, o que reitera a importância da dimensão econômica para os sujeitos. Portanto, os dados aproximaram-se dos resultados obtidos em estudo de Jesús e Ordaz (2006), o qual registrou que os jovens buscavam um trabalho capaz de suprir suas necessidades pessoais e financeiras - o que abarca as dimensões expressiva e instrumental do trabalho, respectivamente (Bajoit \& Frassen, 1967/2007). Essas opiniões assemelhamse aos significados atribuídos ao trabalho em estudos com jovens, que descrevem a atividade laboral como meio de ajudar as famílias, adquirir independência financeira e conquistar liberdade (Asmus e cols., 2005; Campos \& Francischini, 2003; Guimarães \& Romanelli, 2002; Oliveira \& Robazzi, 2001; Tokman e cols., 2003).
Outro aspecto a considerar em relação às maiores médias das definições de trabalho como "produção do que é útil" e "dinheiro" é o registro do papel central da atividade ocupacional na vida dos participantes. O trabalho é uma via importante para a manutenção e cuidado de outras áreas da vida ao propiciar o ingresso de dinheiro e benefícios (Jesús \& Ordaz, 2006). Torna-se significativo para a maioria das pessoas, considerando o tempo que estas devotam para o mesmo cotidianamente nos diversos âmbitos de convívio: família, religião, vida comunitária (Morin, 2004).

A média da amostra total em relação às definições de trabalho (Tabela 4) localizou, em terceiro lugar, o entendimento da palavra como honra. Esta compreensão atravessa diferentes tempos históricos, uma vez que a mesma já estava presente na civilização grega, para a qual o trabalho era classificado como digno e tinha uma função para além da satisfação das necessidades básicas (Nardi, 2006). As concepções protestantistas abrangiam, também, a dimensão honrosa de trabalho, entendendo-o como virtude e meio de atingir a Deus (Gonçalves, 2008).

O entendimento de trabalho como emprego apresentou média intermediária na amostra total (Tabela 4), o que pode estar indicando a abertura dos jovens para novas formas de trabalho, tanto por necessidade quanto por motivação própria. O sentido de emprego expressa o caráter contratual na sociedade salarial, que estabelece um conjunto de regras que se propõem a assegurar os direitos dos trabalhadores (Codo, 2006; Nardi, 2006). Entretanto, a configuração laboral frágil presente nos dias atuais nem sempre propicia este formato de relação trabalhista, o que contextualizaria a localização intermediária desta definição. Além disso, segundo Coutinho e Gomes (2006), trabalho e emprego são vistos de forma diferentes pelos jovens. Emprego possui sentido financeiro/comercial, enquanto trabalho está ligado à satisfação pessoal.

Ainda em relação à variável opinião sobre definições de trabalho, constatou-se, através do teste $t$ de Student, que os jovens trabalhadores em relação aos não trabalhadores 
apresentaram média superior no entendimento de trabalho como esforço 2,21 ( $S D=0,825)(t=3,76 ; d f=6743 ; p<0,0001)$; $1,83(S D=0,816)$ como mercadoria $(t=5,305 ; d f=5108,9$; $p<0,0001) ; 1,85(S D=0,798)$ e como identidade $(t=4,25$; $d f=6296 ; p<0,0001$ ) (Tabela 4). É possível que as médias superiores nestes aspectos estejam relacionadas à vivência laboral dos mesmos.

A definição de esforço pode estar associada às características de um trabalho exigente, que os priva de liberdade e possui rotina rígida. Esta vivência esteve presente em estudo de Fischer e cols. (2003), o qual identificou que os jovens trabalhadores significavam sua experiência laboral como de "muita responsabilidade" e "estressante", uma vez enfrentavam sobrecarga de tarefas, falta de experiência no trabalho e, principalmente, exigências psicossociais para além de suas capacidades e vivências.

A dimensão negativa do trabalho, relacionada às experiências laborais precárias, aproxima-se da própria origem da palavra, vinculada a um instrumento de tortura (Albornoz, 1986; Jacques, 2002; Nardi, 2006), bem como às concepções religiosas judaico-cristãs, as quais atribuíam ao trabalho conotação de castigo e dificuldade inerente ao ser humano (Borsoi, 2002; Gonçalves, 2008; Jacques, 2002; Nardi, 2006).

Já a média superior dos jovens trabalhadores em relação à definição de trabalho como mercadoria explicita o quanto esta atividade está intrinsecamente ligada à remuneração e à dimensão instrumental do trabalho (Bajoit \& Frassen, 1967/2007; Zanini, Fürstenau, Pacini, \& Merlo, 2004), a qual lhes dá subsídios para, por exemplo, comprar suas próprias coisas e auxiliar na renda familiar.

Os jovens trabalhadores também apresentaram média superior em relação à definição de trabalho como identidade. Esta concepção expressa o quanto a atividade executada pelo indivíduo relaciona-se com o que ele é (Jacques, 2003), de forma a contribuir para a constituição de seu mundo psicológico (Albornoz, 1986; Codo, 1997). Nesse sentido, a atividade laboral mostra-se como mediadora da subjetividade (mundo interno) e objetividade (mundo externo), e nessa relação tanto a pessoa quanto a natureza se modificam (Coutinho, 1993; Tittoni, 1994).

\section{Considerações finais}

O presente estudo aproximou-se da vivência laboral dos jovens brasileiros de classe popular. Mediante as variáveis analisadas, foi possível identificar um quadro de fragilidade, uma vez que o contexto do mercado de trabalho se caracteriza como não favorável para esta população. Perde-se de vista que o público juvenil está em processo de formação da sua identidade pessoal e profissional e que o contexto de sua vida particular é influenciado por seu trabalho, bem como o seu trabalho é influenciado por suas vivências pessoais.

A fim de garantir a proteção do jovem trabalhador e, considerando as peculiaridades desta etapa do ciclo vital, o Estatuto da Criança e do Adolescente, através do Decreto $\mathrm{n}^{\circ}$
5598/2005 (Brasil, 2005), propõe-se a assegurar formação técnico-profissional e a realização de atividades compatíveis coma vida escolar e com o desenvolvimento físico, psicológico e moral dos adolescentes. Entretanto, os dados referentes ao contexto de inserção laboral apresentados neste artigo registram uma realidade distante desta proposta.

No que se refere a este contexto, foi possível constatar que os jovens trabalhadores encontram mais oportunidades de trabalho informal e recebem remuneração inferior a um salário mínimo (ainda que se dediquem entre cinco a oito horas diárias). Conclui-se que o(a) jovem está inserido em contexto de trabalho que o vulnerabiliza. A baixa remuneração, a escassez no recebimento de benefícios e a dificuldade de economizar o dinheiro recebido revelaram que o trabalho juvenil não possui um retorno adequado. Este quadro delimita novamente este contexto laboral frágil, uma vez que a dificuldade de economizar, por exemplo, impede que estes jovens trabalhadores possuam uma reserva financeira para planos futuros.

Ainda em relação às atividades de caráter informal, é pertinente considerar também que estas podem adquirir característica protetiva, desde que realizadas com supervisão e acompanhamento adequados, e uma proposta educativa. Por outro lado, a lacuna expressa por um contrato informal pode propiciar a emergência de tarefas de caráter exploratório, $\mathrm{o}$ que caracterizaria fator de risco.

Observa-se, portanto, um contexto que vulnerabiliza o(a) jovem enquanto indivíduo que está formando sua identidade pessoal e profissional. O público juvenil carece de um trabalho com carteira assinada, benefícios trabalhistas e perspectivas de ascensão profissional. As empresas empenhamse em economizar encargos trabalhistas e transformam seus empregados em prestadores de serviços ou autônomos subcontratados (Lima, 2005). Este panorama eleva a fragilidade das experiências ocupacionais deste público, uma vez que, diante da necessidade de sobreviver, contribuir para a renda familiar e buscar sua independência, tornam-se vulneráveis a condições de trabalho degradantes e alienadoras.

Além disso, é preciso considerar que o ser humano relaciona-se com seu contexto de forma dialética, transformando a si mesmo e o mundo ao seu redor. Esta vivência promove o surgimento de significados para a própria experiência laboral do jovem. Em relação ao significado da palavra trabalho, na amostra total, destacaram-se "produção de algo útil" e "dinheiro". Estas dimensões podem estar refletindo a busca por um trabalho que construa algo produtivo para o indivíduo e sociedade, sem perder de vista que o mesmo necessita proporcionar condições de sobrevivência para o jovem e sua família, através da remuneração. Observou-se que o significado de trabalho como emprego ficou em posição intermediária, o que pode estar indicando uma abertura do(a) jovem para novas formas de trabalho - seja por falta de oportunidades de trabalhar com carteira assinada ou por opção. Já as definições "esforço", "identidade" e "mercadoria" obtiveram média superior no grupo de trabalhadores, o que pode estar 
refletindo as percepções que desenvolvem a partir de suas experiências laborais cotidianas, as quais lhes demandam dedicação, lhes proporciona um retorno financeiro, ou ainda, constituem uma vivência formadora de sua identidade.

A partir dos dados expostos, identifica-se que a reversão deste quadro exige esforços no campo educativo e reformas de funcionamento dos mercados. Há de se considerar que a juventude é uma condição que se articula cultural e socialmente em função da idade, da geração, do gênero e da classe social de origem - que proporciona a vivência ou não da moratória juvenil (Margullis \& Urresti, 2008). Dessa forma, o público específico aqui investigado, isto é, jovens de classe popular, encontra-se em situação de vulnerabilidade social no que tange a aspectos educacionais, familiares e, em destaque neste artigo, laborais. Nesse sentido, as reflexões acerca do conceito de moratória juvenil estão de acordo com os resultados aqui expostos, uma vez que ilustra o desequilíbrio na distribuição dos recursos e oportunidades entre os jovens de diferentes níveis sócio-econômicos (Margullis \& Urresti, 2008).

\section{Referências}

Albornoz, S. (1986). O que é trabalho? (6a ed). São Paulo: Brasiliense.

Amazarray, M. R., Dutra-Thomé, L., Poletto, M., \& Koller, S. (2007). Perspectivas acerca do trabalho infantojuvenil: Ideologias, subjetividade e saúde do trabalhador. Laboreal, 3, 22-28.

Asmus, C. I. R. F, Raymundo, C. M. R., Barker, S. L., Pepe, C. C. C. A., \& Ruzany, M. H. (2005). Atenção integral à saúde de adolescentes em situação de trabalho: Lições aprendidas. Ciência e Saúde Coletiva, 10, 953-960.

Bajoit, G., \& Franssen, A. (2007). O trabalho, busca de sentido. In O. Fávero, M. P. Spósito, P. Carrano, \& R. R. Novaes. (Orgs.), Juventude e contemporaneidade (93123). Brasília: UNESCO. (Publicado originalmente em 1967)

Bastos, A. V. B. (2003). Psicologia organizacional e do trabalho: Que resposta estamos dando aos desafios contemporâneos da sociedade brasileira? In O. H. Yamamoto \& V. Gouveia (Orgs.), Construindo a psicologia brasileira: Desafios da ciência e prática psicológica. São Paulo: Casa do Psicólogo.

Batista, A. S., \& Codo, W. (2002). O trabalho e o tempo. In M. G. Jacques \& W. Codo (Eds.), Saúde mental e trabalho: Leituras (pp. 401-420). Petrópolis, RJ: Vozes.

Borsoi, I. C. F. (2002). Os sentidos do trabalho na construção civil: O "esforço alegre" sem a alegria do esforço. In M. G. Jacques \& W. Codo (Orgs.), Saúde mental e trabalho: Leituras (pp. 309-324). Petrópolis, RJ: Vozes.

Brasil. (1990). Estatuto da Criança e do Adolescente: Lei Federal 8069/1990. Brasília: Diário Oficial da União.

Brasil. (2005). Decreto 5598/2005. Brasília: Diário Oficial da União.
Câmara, S. G., Sarriera, J. C., \& Pizzinato, A. (2004). Que portas se abrem no mercado de trabalho para os jovens em tempos de mudança? In J. C. Sarriera, K. B. Rocha, \& A. Pizzinato (Orgs.), Desafios do mundo do trabalho (pp. 73-114). Porto Alegre: EDIPUCRS.

Camarano, A. A., \& Melo, J. L. (2006). Considerações finais: Transição para a vida adulta ou vida adulta em transição? In A. A. Camarano (Org.), Transição para a vida adulta ou vida adulta em transição? Rio de Janeiro: IPEA.

Campos, H. R., \& Francischini, R. (2003). Trabalho infantil produtivo e desenvolvimento humano. Psicologia em Estudo, 8, 119-129.

Codo, W. (1997). Um diagnóstico do trabalho (em busca do prazer). In A. Tamayo, J. E. Borges-Andrade, \& W. Codo (Orgs.), Trabalho, organizações e cultura (pp. 21-40). São Paulo: Cooperativa de Autores Associados.

Codo, W. (2006). Um diagnóstico do trabalho: Em busca do prazer. In W. Codo (Org.), Por uma psicologia do trabalho: Ensaios recolhidos (pp. 75-96). São Paulo: Casa do Psicólogo.

Codo, W., \& Lago, K. (2006). Sobre o verbo, o trabalho e a loucura: Abordando a saúde mental através do trabalho. In W. Codo (Org.), Por uma psicologia do trabalho: Ensaios recolhidos (pp. 255-264). São Paulo: Casa do Psicólogo.

Conselho Federal de Psicologia. (2000). Resolução para pesquisa com seres humanos. Resolução n. 016/2000. Brasília, DF.

Conselho Nacional de Saúde. (1996). Resolução n. 196/1996, 16 de outubro de 1996. Brasília, DF.

Coutinho, M. C. (1993). Subjetividade e trabalho. In D. H. P. Soares-Lucchiari (Org.), Pensando e vivendo a orientação profissional (5a ed., pp. 117-122). São Paulo: Summus.

Coutinho, M. C., \& Gomes, J. S. (2006). Sentidos do Trabalho: Reflexões a partir de uma oficina vivencial desenvolvida com jovens. Pesquisas e Práticas Psicossociais, 1(1), 1-13.

Fischer, F. M., Oliveira, D. C., Teixeira, L. R., Teixeira, M. C. T. V., \& Amaral, M. A. (2003). Efeitos do trabalho sobre a saúde de adolescentes. Ciência e Saúde Coletiva, 8, 973-984.

Guimarães, R. M., \& Romanelli, G. (2002). A inserção de adolescentes no mercado de trabalho através de uma ONG. Psicologia em Estudo, 7, 117-126.

Gonçalves, C. M. (2008). Pais aflitos, filhos com o futuro incerto? Um estudo sobre a influência das famílias na orientação dos filhos. Lisboa, FCG/FCT.

Instituto Brasileiro de Análises Sociais e Econômicas. (2005). Juventude brasileira e democracia: Participação, esferas e políticas públicas: Ibase/Polis. Rio de Janeiro. (Relatório Final de pesquisa)

Instituto Brasileiro de Geografia e Estatística. (2000). População jovem no Brasil: A dimensão demográfica. Recuperado em 30 junho 2006, de <http:// www.ibge. gov.br> 
Instituto Cidadania. (2003). Perfil da juventude brasileira. Criterium Assessoria em Pesquisa, Instituto Cidadania, Instituto de Hospitalidade e SEBRAE. Recuperado em 30 julho 2006, de <http://www.projetojuventude.org.br>

Jacques, M. G. (2002). Doença dos nervos: Uma expressão da relação entre saúde/doença mental. In M. G. Jacques, \& W. Codo (Orgs.), Saúde mental e trabalho: Leituras (pp. 98-111). Petrópolis, RJ: Vozes.

Jacques, M. G. (2003). Abordagens teórico-metodológicas em saúde/doença mental e trabalho. Psicologia $e$ Sociedade, 15(1), 97-116.

Jesús, M., \& Ordaz, M.G. (2006). El significado del trabajo: Estudio comparativo entre jóvenes empleados y desempleados. Segunda Época, 25(2), 64-77.

Koller, S. H., Cerqueira-Santos, E., Morais, N. A., \& Ribeiro, J. (2005). Juventude brasileira: Relatório técnico. Washington DC: World Bank.

Lehman, Y. P. (1998). Globalização: Os desafios da orientação profissional. In Congresso Interno do IPUSP, 4. São Paulo: IPUSP.

Lima, S. M., \& Minayo-Gomes, C. (2003). Modos de subjetivação na condição de aprendiz: Embates atuais. História, Ciências e Saúde: Manguinhos, 10, 931-953.

Lima, L. F. (2005). (Des)emprego tecnológico na indústria metalúrgica: Estudo de caso sobre a W3 Indústria Metalúrgica Ltda: Ponta Grossa. Tese de mestrado nãopublicada, Universidade Estadual de Ponta Grossa, Ponta Grossa, PR.

Martins, H. H. T. S. (2000). A juventude no contexto da restruturação produtiva. In H. W. Abramo, M. V. Freitas \& M. P. Sposito (Orgs.), Juventude em Debate (pp. 1330). São Paulo: Cortez.

Margullis, M., \& Urresti, M. (2008). La juventud es más que una palabra. In M. Margullis (Ed.), La juventud es más que una palabra: Ensaios sobre cultura y juventud (pp. 13-30). Buenos Aires: Biblos.

Mattos, R. A. (1992). De recursos a seres humanos: O desenvolvimento humano na empresa. Brasília: Livre.

Morin, E. M. (2004). The meaning of work in modern times. Congress on Human Resources Management, 10. Rio de Janeiro.

Nardi, H. C., \& Yates, D. B. (2005). Transformações contemporâneas do trabalho e processos de subjetivação: Os jovens face à nova economia e à economia solidária. Estudos de Psicologia, 10, 95-103.

Nardi, E. C. (2006). Ética, trabalho e subjetividade: Trajetórias de vida no contexto das transformações do capitalismo contemporâneo. Porto Alegre: Editora do UFRGS.

Oliveira, B. R. G., \& Robazzi, M. L. C. C. (2001). O trabalho na vida dos adolescentes: Alguns fatores determinantes para o trabalho precoce. Revista Latino-americana de Enfermagem, 9(3), 83-89.

Organización Internacional del Trabajo. (2005). A OIT $e$ o emprego de jovens. Genebra: OIT. Recuperado em fevereiro 2009, de http://www.oitbrasil.org.br/prgatv/prg_esp/emp_form_jov.php
Organização Internacional do Trabalho. (2009). Panorama laboral 2008: America Latina y El Caribe. Lima: Oficina.

Pesce, R. P, Assis, S. G. Santos, N., \& Oliveira, R. V. C. (2004). Risco e proteção: Em busca de um equilíbrio promotor de resiliência. Psicologia: Teoria e Pesquisa, 20, 135-143.

Romanelli, G. (1997). Famílias de classes populares: Socialização e identidade masculina. Cadernos de Pesquisa NEP, 3(1-2), 25-34.

Sapienza, G., \& Pedromônico, M. R. M. (2005). Risco, proteção e resiliência no desenvolvimento da criança e do adolescente. Psicologia em Estudo (Maringá), 10, 209-216.

Sarriera, J. C., Schwarcz, C., \& Câmara, S. G. (1996). Bemestar psicológico: Análise fatorial da escala de Goldberg (GHQ-12) numa amostra de jovens. Psicologia: Reflexão e Crítica, 9, 293-306.

Sarriera, J. C., Silva, M. A., Kabbas, C. P., \& Lopes, V. B. (2001). Formação da identidade ocupacional em adolescentes. Estudos de Psicologia, 6, 27-32.

Sato, L. (2002). Saúde e controle no trabalho: Feições de um antigo problema. In M. G. Jacques, \& W. Codo (Eds.), Saúde mental e trabalho: Leituras (pp. 31-49). Petrópolis, RJ: Vozes.

Soares, D. H. P. (2001). A escolha profissional do jovem ao adulto. São Paulo: Summus Editorial.

Souza, L. B., \& Figueiredo, M. A. C. (2004). Qualificação profissional e representações sobre trabalho e qualidade de vida. Paidéia (Ribeirão Preto), 14, 221-232 .

Tittoni, J. (1994). Subjetividade e trabalho. Porto Alegre: Ortiz.

Traverso-Yépez, M. (2002). Trabalho e saúde: Subjetividades em um contexto de precariedade. In A. M. M. Mendes, L. O. Borges, \& M. C. Ferreira (Orgs.), Trabalho em transição, saúde em risco (pp. 111-131). Brasília: Editora Universidade de Brasília.

Tolfo, S. R., \& Piccinini, V. (2007). Sentidos e significados do trabalho: Explorando conceitos, variáveis e estudos empíricos brasileiros. Psicologia \& Sociedade, 19 (n. esp.), 38-46.

Tokman, V. E.; Corrochano, M. C.; Gouv A, J. L.(2003). Desemprego Juvenil no Cone Sul: uma análise de década. Opções PROSUR, Fundação Friedrich Ebert Stiftung.

Zanini, P., Fürstenau, C. R., Pacini, L., \& Merlo, A. R. C. (2004). As transformações no serviço público e a saúde dos trabalhadores da seguridade social de Porto Alegre. In A. R. M. Crespo (Ed.), Saúde do trabalhador no Rio Grande do Sul: Realidade, pesquisa e intervenção (pp. 361-378). Porto Alegre: Editora da UFRGS.

Watarai, F., \& Romanelli, G.(2005). Trabalho e identidade de adolescentes do sexo masculino de camadas populares. In Proceedings of the Simpósio Internacional do Adolescente, 1. São Paulo. 
Luciana Dutra Thomé é doutoranda em Psicologia pelo Programa de Pós-graduação, Instituto de Psicologia da Universidade Federal do Rio Grande do Sul, bolsista CAPES.

Alice Queiroz Telmo é graduanda em Psicologia pela Faculdade de Psicologia da Pontifícia Universidade Católica do Rio Grande do Sul.

Silvia Helena Koller é Professora do Instituto de Psicologia da Universidade Federal do Rio Grande do Sul campus da Saúde.

Recebido: 28/08/2009

$1^{a}$ Revisão: $23 / 11 / 2009$

$2^{a}$ Revisão: $13 / 02 / 2010$

Aceite final: 01/03/2010 